\title{
Assessment of Toxicity Potential of Sedimentary PAHS from Refome Lake, South-East Nigeria over the Last Century
}

\author{
Inyang 0. Oyo-Ita1 ${ }^{*}$, Emmanuella E. Oyo-Ita2 ${ }^{2}$, Ekpo 0. Ikip ${ }^{1}$, Bassey B. Asuquo ${ }^{1}$, Orok E. Oyo-Ita ${ }^{1}$ \\ ${ }^{1}$ Environmental/Organic Geochemistry Research Group, Department of Pure and Applied Chemistry, University of Calabar, \\ Calabar, Nigeria \\ ${ }^{2}$ Xi'an Shiyou University, Xi'an, China \\ Email: *inyangoyoita@yahoo.com
}

How to cite this paper: Oyo-Ita, I. O., Oyo-Ita, E. E., Ikip, E. O., Asuquo, B. B., \& Oyo-Ita, O. E. (2020). Assessment of Toxicity Potential of Sedimentary PAHS from Refome Lake, South-East Nigeria over the Last Century. Journal of Geoscience and Environment Protection, 8, 1-15. https://doi.org/10.4236/gep.2020.81001

Received: November 12, 2019

Accepted: January 6, 2020

Published: January 9, 2020

Copyright $\odot 2020$ by author(s) and Scientific Research Publishing Inc. This work is licensed under the Creative Commons Attribution International License (CC BY 4.0).

http://creativecommons.org/licenses/by/4.0/

\begin{abstract}
In this study, toxic equivalent factors and sediment quality guidelines were employed for the assessment of toxicity potential of PAHs in 2 sediment cores collected from the center (RC) and shoreline (RS) of Reforme lake, SE Nigeria over the last $\sim 1$ century. Boundary cross plots of isomeric ratios such as Ant/Ant + Phe (>0.1) vs. Fl/Fl $+\mathrm{Pyr}(>0.4)$ and $\mathrm{BaA} / \mathrm{BaA}+$ Chry (>0.35) vs. Icdp/Icdp + Bper $(>0.2)$ indicated biomass combustion/domestic coal utilization as the main sources of PAHs input. The result revealed toxicity unit indices (TU1, 1.22 - 1.57) for the two cores were above the thresholds of no effect. The highest TU1 value found in the near-bottom layer (RS5, $20-25 \mathrm{~cm}$ ) of the RS corresponding to geological time-frame $\sim 1930-1947$ coincided with the period of inhabitation by the European settlers along the lake's catchments when coal or coal products utilization for domestic and recreational purposes was at its peak. On the other hand, TU2 values were $<1$ at all depth intervals, revealing unlikely PAH effects to resident organisms. Total toxicity equivalency factors (TEqFs) for the surface sediment of RS and RC were 9.29 ng/g TEqFs and $9.16 \mathrm{ng} / \mathrm{g}$ TEqFs, respectively, and indicated that more attention should be paid to BaPyr accumulation in the lake's sediment.
\end{abstract}

\section{Keywords}

Toxicity, PAHs, Refome Lake, Sediment Cores, Assessment, Source

\section{Introduction}

A class of fused ring aromatic compounds commonly referred to as polycyclic aromatic hydrocarbons (PAHs) had been listed by US EPA as compounds of 
public concern as a consequence of their capacity to induce cancer formation and caused genetoxicity, immunotoxicity and teratogenicity as well as reproductive toxicity (Christensen \& Arora, 2007). Their ubiquity may not only be associated with their persistence in the environment but also due to their occurrence naturally (crude oil, forest fires or creates) as well as being products from incomplete combustion of organic matter and burning of fossil fuels. They have high adsorption capacity towards solid matrices or particulate matter due to their hydrophobic nature (Oyo-ita et al., 2016). Thus, they are widely used for environmental monitoring purposes (Liu et al., 2007; Oyo-ita \& Oyo-ita, 2012; Oyo-ita et al., 2013).

As a potential source of contamination of aquatic environment, contaminated sediment may pose a serious threat to wildlife and humans via food chain. Hence, the fate and the toxicity potential in sediment of PAHs have provoked considerable concern. More so, since the sources of PAHs are diverse because they are generated by multiple activities, it becomes urgent and necessary for source identification and apportionment to be undertaken for future environmental management strategy.

According to the Ordinance on water protection, sediments are considered as part of the surface waters and should not accumulate any persistent pollutant in order to protect the aquatic life (OEaux, 1998). Today, sediment quality assessment methods used worldwide are based exclusively on a chemical approach, which utilizes environmental concentrations and compares these levels to reference standards. In Nigeria, for example, there are still no trigger values on sedimentary organic contaminants with only little systematic analysis of the sediment load. In addition, studies on toxicity potential of organic contaminants and sediment quality assessment are scarce or not often undertaken, not only in the Niger Delta drainage basin (including lakes) but also in many tropical sub-saharan African countries.

Environmental risk assessment enables toxic effect of sedimentary PAHs in lakes to be estimated. Sediment quality guidelines (SQGs; CCME, 2002) have recently been employed to identify areas with high toxicological risk (Romano et al., 2008). The method for estimation of toxicity in remote lake's sediment based on SQGs is presented here. This approach enabled the potential toxicological effect of PAHs to be compared within and between cores from Reforme lake and area or layer of highest toxicological risk to be identified. Moreso, recommendations for the characterization of lake sediments are lacking and quality criteria missing in the region. Thus, the study is part of a regional project aimed at providing recommendations for the assessment of sediment toxicity in Nigeria. In addition, the study aimed to provide a basis for discussion to help experts and stakeholders take decisions regarding the applicability of sediment quality assessment criteria for future management strategy in Nigeria.

Refome Lake was chosen for the study on the following basis: 1) unique relief that allows minimal run-off, 2) investigation of inputs from atmospheric precipitation is easy and 3) authoustonous production can be assessed readily. A few 
organic geochemical studies that delineated the historical trends in the distribution of natural and anthropogenic biomarkers and PAHs have been reported previously by us for the lake (Oyo-ita et al., 2016; Oyo-ita et al., 2017). The present report is part of an overall project entitled "Organic Tracers of Toxicity in the Environment of Niger Delta (OTTEND)" aimed at assessing the potential risk and toxicity posed by certain pollutants in the drainage basin of Niger Delta. The main objectives of the study were to; 1) Determine the historical trend of PAHs contamination in sediment cores from the Refome lake over the last century, 2) identify possible sources of PAHs contamination, 3) assess sediment toxicity potential of PAHs in the lake and 4) identifies site and/or layer of high toxicological risk.

Detailed information about the study area is as described in (Oyo-ita et al., 2017; CRBDA, 1982; Ekwueme et al., 1995). Briefly, Refome Lake is a remote semi-enclosed small lake inthe southeast Niger Delta drainage basin, located at $80 \mathrm{E}$ and $5.80 \mathrm{~N}$ inCross River State, Nigeria with a surface area of $\sim 2 \mathrm{~km}^{2}$ and a maximum depth of $\sim 10 \mathrm{~m}$ at the center. Underground spring water constitutes the primary source of water. Occasional influx from adjoining Cross River estuary, particularly during intense rainfall (wet season), slightly enlarges the volume of the lake water $\left(\sim 21.01 \times 10^{5} \mathrm{~m}^{3}\right)$. The fluxes ranged from 65.43 to 102.61 $\mathrm{ng} \cdot \mathrm{m}^{-2} \cdot \mathrm{yr}^{-1}$ (mean $\left.78.41 \pm 3.52 \mathrm{ng} \cdot \mathrm{m}^{-2} \cdot \mathrm{yr}^{-1}\right)$.

Prior to Nigerian independence in 1960, Europeans (administrators'/military aides)occupied the lake catchments against the will of the villagers as the lake water served as a recreational/fishery facility-reliable historical information had it that most of the fishing activity took place mainly towards the center of the lake. This imposition in later years heralded the commencement of extensive farming activity and foot path-extension exercise involving tree logging/forest clearing and burning. Post independent Nigeria saw the departure of the white settlers and the subsequent resettlement of the villagers along the lake's catchments. Prior to the time of discovery of oil in commercial quantity in Nigeria in 1956, utilization of imported refined petroleum products was limited as indigenous coal was the main source of energy in the country.

The geology of the study area is characterized by the Afikpo Formation, which is part of the lower Benue trough, within the Cretaceous sedimentary basin of southeastern Nigeria. The bedrock and soil of the region are rich in limestone (Silliman \& Shelske, 2003).

\section{Materials and Methods}

\subsection{Materials}

The following suprasov-grade solvents used were provided by Dr. Ehrenstofer GmbH-Augsburg: methanol, dichloromethane, iso-octane, ethyl acetate, n-hexane and acetone used Germany. anhydrous $\mathrm{NaSO}_{4}$ and $\mathrm{AL}_{2} \mathrm{O}_{3}$ active neutral $(0.063-0.200 \mathrm{~mm})$ were obtained from Merck-Hohenbrunn, Germany. The following perdeuterated PAHs were used as surrogates: naphtha- 
lene-d8 (98\%), anthracene-d10 (98\%), pyrene-d10 (98\%), benzo[a]pyrene-d12 (98\%), benz[a]anthracene-d12 (98\%) (purchased from Cambridge Isotope Laboratory (Ambovar, USA) and triphenylamine (TPhA) as internal standard. Pre-cleaning of the vessels for analysis was carried out with ethyl acetate followed by acetone and heated at $450^{\circ} \mathrm{C}$ overnight.

\subsection{Sample}

Two cores (RC and RS; $30 \mathrm{~cm}$ long) separated from each other by $300 \mathrm{~m}$ were collected towards the center and shoreline of Refome Lake, respectively using a calibrated PVC corer on the $12^{\text {th }}$ August, 2014. Each core was sectioned into six sections $(5 \mathrm{~cm})$ making a total of 12 sub-samples. Samples were placed on pre-cleaned aluminum foil, wrapped, labeled and kept in a cooler of ice to prevent microbial activity. They were subsequently transferred to the laboratory, stored in a deep freeze at $-20^{\circ} \mathrm{C}$ until further processing [12]. They were later freeze-dried, lightly crushed and sieved to pass through $<65 \mu \mathrm{m}$ mesh and kept in a deep freeze at $-20^{\circ} \mathrm{C}$ prior to extraction.

\subsection{Radiometric Analysis}

Samples were analyzed using direct gamma assay (OrtecHPGe GWL series well-type coaxial low background intrinsic Ge detectors) of 50\% relative efficiency covered in a $10 \mathrm{~cm} \mathrm{~Pb}$ shielding with $\mathrm{Cd}, \mathrm{Cu}$ and plastic lining, using Canberra Genie 2000 as software. $\gamma$ emissions at $46.5 \mathrm{keV}$ were used in the determination of ${ }^{210} \mathrm{~Pb}$ whereas $295 \mathrm{keV}$ and $352 \mathrm{keV} \gamma$-rays emitted were used for the determination of ${ }^{226} \mathrm{Ra}$ via its daughter isotope ${ }^{214} \mathrm{~Pb}$ following storage in sealed containers for three weeks to allow for radioactive equilibration. Determination of activity concentrations $\left(\mathrm{Bq} \cdot \mathrm{kg}^{-1} \mathrm{dw}\right)$ of ${ }^{210} \mathrm{~Pb}_{\text {sup }}$ and ${ }^{214} \mathrm{~Pb}$ were performed. ${ }^{210} \mathrm{Pbxs}$ activity concentrations calculated for each sample was a reflection of a difference between ${ }^{210} \mathrm{Pbtot}$ and ${ }^{210} \mathrm{~Pb}$ sup. ${ }^{24} \mathrm{~Pb}$ in equilibrium with ${ }^{220} \mathrm{Ra}$ was used for the estimation of ${ }^{210} \mathrm{~Pb}_{\text {sup }}$. Due to constant geometry of the samples, no individual self-attenuation corrections were applied for ${ }^{210} \mathrm{~Pb}$. Instead, efficiency values that were used was obtained experimentally with test sources of similar geometry. Radiometric dates were calculated from the ${ }^{210} \mathrm{~Pb}$ record using procedures described by (Appleby, 1998).

\subsection{Grain Size Determination and Elemental Analysis}

Sediment grain sizes were analyzed using a laser particle seizer (LS 200, Beckmann-Coulter) with a mesh ranging from $0.375 \mu \mathrm{m}$ to $1000 \mu \mathrm{m}$. A detailed presentation of the analytical procedure is as described in (Shi et al., 2006). De-carbonation of freeze-dried pre-weighed samples was carried out repeatedly until bubbles stopped using $87 \%$ syrupy ortho phosphoric acid and repeatedly rinsed in de-ionized water until $\mathrm{pH}$ of about 7. The total organic carbon (TOC) content was determined by thermal conductivity and flash combustion at $1024^{\circ} \mathrm{C}$ detection in a CHNS Elemental Analyser, Carlo Erba 1108. The analysis was conducted in triplicate. 


\subsection{Extraction and Clean-Up}

$0.1 \mathrm{ml}$ of Perdeuterated surrogates such as naphthalene- $d 8$, anthracene- $d 10$, pyrene- $d 10$, benzo[a]pyrene- $d 12$, benz[a] anthracene- $d 12$ were "spiked" on samples prior to extraction protocol and triphenylamine (TPhA) was used as internal standard. About $1 \mathrm{~g}$ of each sample was extracted $3 \mathrm{x}$ by sonication (ultrasons 9 $\mathrm{L} ; 360 \mathrm{~W}$ average power output and mean operating frequency of $40 \mathrm{KHz}$ ) for 30 min with $15 \mathrm{ml}$ of solvent mixture (acetone/hexane; 1:1 v/v). After centrifugation at $3500 \mathrm{rpm}$ for $10 \mathrm{~min}$, the clear supernatants were removed and the combined extracts were concentrated to near-dryness under a stream of pure $\mathrm{N}_{2}$ and re-dissolved in $\sim 0.5 \mathrm{ml} \mathrm{n}$-hexane prior to cleanup.

Cleanup protocol was conducted in an open glass column (adsorption chromatography) packed with $1 \mathrm{~g}$ anhydrous sodium sulfate (top), 2 g neutral alumina (middle; activated at $400^{\circ} \mathrm{C}, 5 \%$ water deactivated) and glass wool (bottom). The eluent was concentrated to an accurate $300 \mu \mathrm{L}$ by a gentle stream of $\mathrm{N}_{2}$ gas and preserved in a dark-brown vial prior to gas chromatography-mass spectrometry (GC-MS) injection.

\subsection{Instrumental Analysis and Quality Assurance/Control}

Aromatic fractions were analyzed using a TRACE GC-MS Thero-Finnigan (Manchester, UK) in the electron impact (EI) mode at $70 \mathrm{eV}$. A 30-m, 0.25-mm-id capillary column coated with $0.25 \mu \mathrm{m}$ ZB-5MS adsorbent (PhenomenexZebron; USA) was used. Helium was used as carrier gas with a constant flow rate of 1.2 $\mathrm{ml} / \mathrm{min}$. The injector temperature, in "splitless" mode, was held at $280^{\circ} \mathrm{C}$ and the purge valve was activated $50 \mathrm{~s}$ after the injection. Column temperature was held at $60^{\circ} \mathrm{C} / \mathrm{min}$, then the temperature was increased to $200^{\circ} \mathrm{C}$ at $10^{\circ} \mathrm{C} / \mathrm{min}$ and finally to $320^{\circ} \mathrm{C}$ at $4.8^{\circ} \mathrm{C} / \mathrm{min}$, holding that temperature for $10 \mathrm{~min}$. Transfer line and ion source temperatures were held at $250^{\circ} \mathrm{C}$ and $200^{\circ} \mathrm{C}$, respectively. Data were acquired in the selected ion monitoring (SIM) mode with 6 min of solvent delay and processed by the X-calibur Thermo Finnigan software (San Jose, California, USA).

For every batch of 2-5 samples, one procedural blank was run to check background contamination accompanying the extraction and clean-up protocols. To eliminate background contamination, subtraction of the mean of the analytical blanks from the concentrations of PAHs was carried out in order to correct the $\mathrm{PAH}$ concentrations. Deuterated PAHs were used for both quantification and recovery corrections. Samples analysis was conducted $3 \times$ and relative standard deviations (RSDs) of $<20 \%$ were obtained. The mean percentage recovery was $84 \% \pm 11 \%(60 \%-130 \%)$. The average signal of the blanks plus $3 \times$ the standard deviation of the signal of the blanks was taken as the estimated limits of detection (LOD), while the average signal of the blanks plus $10 \times$ the standard deviation of the signal of the blanks was taken as the estimated limits of quantification (LOQ).

The parent and alkyl PAHs in the samples were identified on the basis of re- 
tention time and ion fragment profile compared against authentic standards, whereas quantification was conducted using multipoint internal calibration method. Detector response versus amounts injected was plotted (a calibration curve) for the quantification of each target compound. All measurements were carried out in the linear ranges for each target compound. In few cases, re-dilution and re-injection of samples were performed to fit within the linear range of the instrument (Figure 1).

\section{Results and Discussion}

\subsection{Sediment Bulk Characteristics}

Results of the distribution of grain size and radiometric analyses are presented in Table 1. The two cores (RS and RC) were predominated by sand fraction ranging from $62.5 \%$ at the near-bottom layer of RC (RC5, $20-25 \mathrm{~cm})$ to $76.1 \%$ at the most recent top layer of RS (RS1, $0-5 \mathrm{~cm}$; mean $67.8 \% \pm 3.4 \%$ ). The silt fractions were in the range $19.7 \%-28.0 \%$, minimizing and maximizing at the top layer (RS1, $0-5 \mathrm{~cm}$ ) of RS and middle layer of RC (RC4, $15-20 \mathrm{~cm}$ ), respectively, with a mean of $24.6 \% \pm 2.9 \%$. Whereas the clay contents ranged from $4.2 \%$ at the top layer (RS1, $0-5 \mathrm{~cm}$ ) of RS to $10.5 \%$ at the near-bottom layer of RC (RC5, $20-25 \mathrm{~cm}$; mean $7.46 \% \pm 3.4 \%$ ). The percentage of sand was relatively high in the upper layers (RC6 and RS6) with the highest value (76.1\%) recorded for RS6, followed by RC6 (72.60\%). The middle and lower horizons exhibited mean $\%$ sand of $69.9 \% \pm 3.1 \%$ and $65.7 \% \pm 2.9 \%$, respectively (Table 1 ).

Generally, the sand fraction was higher in the RS than in the RC probably due to its proximity to terrigenous material and decreased with increasing depth. Also, the variability in grain size distribution reflected the sediment varying

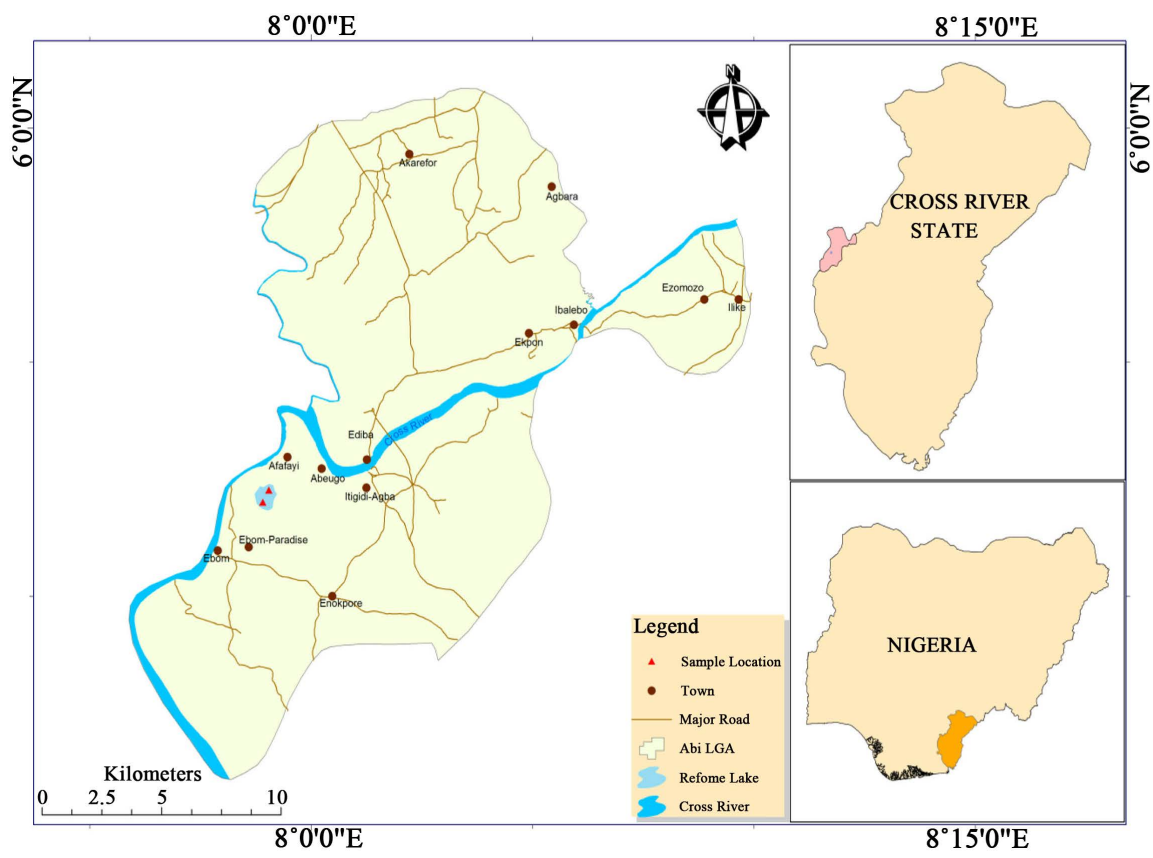

Figure 1. Map of the study area indicating sampling points. 
Table 1. Bulk geochemical properties for RS and RC cores.

\begin{tabular}{|c|c|c|c|c|c|c|c|c|}
\hline Sample & $\begin{array}{l}\text { Sub-bottom } \\
\text { depth }(\mathrm{cm})\end{array}$ & $\begin{array}{c}\text { Water } \\
\text { column }(\mathrm{m})\end{array}$ & Sand $(\%)>0.1 \mathrm{~mm}$ & Silt $(\%)>0.05 \mathrm{~mm}$ & Clay $(\%)>0.003 \mathrm{~mm}$ & Period & $\begin{array}{l}\text { Age } \\
\text { (yr) }\end{array}$ & Coordinate \\
\hline RS1 & $0-5$ & 6 & 76.1 & 19.7 & 4.2 & $1997-2014$ & 16.6 & \\
\hline RS2 & $5-10$ & 6 & 73.1 & 21.0 & 5.9 & 1980-1997 & 33.2 & \\
\hline RS3 & $10-15$ & 6 & 68.4 & 24.5 & 7.1 & $1964-1980$ & 49.8 & \\
\hline RS4 & $15-20$ & 6 & 69.4 & 23.1 & 7.5 & $1947-1964$ & 66.4 & $\begin{array}{l}5^{\circ} 871^{\prime} \mathrm{N} \\
7^{\circ} 984^{\prime} \mathrm{E}\end{array}$ \\
\hline RS5 & $20-25$ & 6 & 67.0 & 24.0 & 9.0 & $1930-1947$ & 83.0 & \\
\hline RS6 & $25-30$ & 6 & 67.5 & 24.0 & 8.5 & 1914-1930 & 99.6 & \\
\hline Range & & - & $76.1-67.0$ & $24.0-19.7$ & $9.0-4.2$ & & & \\
\hline Mean & & - & $69.9 \pm 3.1$ & $26.3 \pm 1.4$ & $7.0 \pm 2.1$ & & & \\
\hline $\mathrm{RC} 1$ & $0-5$ & 10 & 72.6 & 22.2 & 5.2 & $1998-2015$ & 17 & \\
\hline $\mathrm{RC} 2$ & $5-10$ & 10 & 69.4 & 25.0 & 5.6 & 1981-1998 & 34 & \\
\hline $\mathrm{RC} 3$ & $10-15$ & 10 & 64.0 & 27.0 & 7.0 & $1965-1981$ & 51 & \\
\hline $\mathrm{RC} 4$ & $15-20$ & 10 & 63.0 & 28.0 & 9.0 & $1948-1965$ & 68 & $5^{\circ} 866^{\prime} \mathrm{N}$ \\
\hline RC5 & $20-25$ & 10 & 62.5 & 27.5 & 10.0 & 1931-1948 & 85 & $7^{\circ} 981^{\prime} \mathrm{E}$ \\
\hline RC6 & $25-30$ & 10 & 62.5 & 27.0 & 10.5 & $1914-1931$ & 102 & \\
\hline Range & & - & $72.6-62.5$ & $28.0-22.2$ & $10.5-5.2$ & & & \\
\hline Mean & & - & $65.7 \pm 2.9$ & $23.0 \pm 1.7$ & $7.9 \pm 2.3$ & & & \\
\hline
\end{tabular}

capacity to retain organic matter as well as the slight variation in sediment accumulation rates between the two cores (Table 1).

The cores were undisturbed as evident in the preservation of fine-sediment laminations; sediment interface and clear water, thus, having little influence on radio-dating results. In other words, the dated cores did not experience any periods of surface mixing in the sediment column and generally showed a well-defined chronology of deposition. An estimated mean sediment accumulation rate (SAR) of $0.3 \pm 0.07 \mathrm{~cm} \cdot \mathrm{yr}^{-1}$ was recorded for the cores. Age estimation of the cores reflected a mean provisional record of one century of sediment accumulation history. Accumulation records of the dated sediment ranged from $\sim 1914$ (period of amalgamation of southern and northern protectorates in Nigeria) to 2014 (period of centenary celebration of existence as a nation; Table 1). The relatively low input of terrigenous material associated with the unique relief feature of the lake region may account for the slight variation in the SAR between the two cores (Table 1).

\subsection{Source Characterization}

A total of 13 EPA priority listed PAHs were identified and quantified in the two cores including naphthalene (Nap), fluorene (Flu), phenanthrene (Phe), anthracene (Ant), fluoranthene ( $\mathrm{Fl})$, chrysene (Chry), pyrene (Pyr), benzo(a)anthracene (BaA), benzo(k)fluoranthene (BKF), indeno(1,2,3-cd)pyrene (lcdP), benzo(a)pyrene 
(BaPyr), dibenzo(a,h)anthracene (DBA) and benzo(ghi)perylene (BPer). Other non-priority listed PAHs detected included perylene (Pery), dibenzothiophene (DBT) and retene (Ret).

Identification of potential sources of pollution is important for developing control strategies in environmental study. Diagnostic isomers of PAHs ratios have frequently been adopted for purposes of source discrimination based on the idea that paired isomers are weathered to a similar extent and that the ratios do not change from source to receptor points. Guo et al. (2011) commonly used ratios include Ant/Ant + Phe, BaA/BaA + Chry, Fl/Fl + Pyr, Icdp/Icdp + Bper etc. Values of Icdp/Icdp + Bper $<0.2$ and $\mathrm{Fl} / \mathrm{Fl}+\mathrm{Pyr}<0.4$ usually indicate a petroleum source, whereas values for these ratios $>0.5$ imply a coal, or wood/grass combustion source. $\mathrm{Fl} / \mathrm{Fl}+\mathrm{Pyr}$ ratios between $0.4-0.5$ and the Icdp/Icdp + Bper ratio between 0.2 - 0.5 indicate a liquid fossil fuel combustion source (NOAA, 1998). The characteristic PAH diagnostic ratios for the cores of Reforme Lake are presented in Table 2. Ant/Ant + Phe and $\mathrm{BaA} / \mathrm{BaA}+$ Chry for RC were 0.67 $\pm 0.03(0.62-0.70)$ and $0.47 \pm 0.01(0.48-0.49)$, respectively and $0.35 \pm 0.05$ $(0.28-0.40)$ and $0.47 \pm 0.01(0.48-0.50)$, respectively for RS. They both suggest a pyrogenic source input to the lake. With the values of $\mathrm{Fl} / \mathrm{Fl}+\mathrm{Pyr}$ and Icdp/Icdp + Bper being $0.54 \pm 0.09(0.48-0.70)$ and $0.65 \pm 0.02(0.63-0.68)$, respectively, for $\mathrm{RC}$ and $0.52 \pm 0.02(0.48-0.54)$ and $0.61 \pm 0.04(0.56-0.65)$, respectively, for RS, it therefore beconcluded that $\mathrm{PAH}$ input to Reforme lake were mainly sourced from domestic coal utilization and wood/grass burning.

Boundary cross plots of Ant/Ant + Phe versus Fl/Fl + Pyr (Figure 2(a) and Figure 2(b)) and BaA/BaA + Chry versus IcdP/IcdP + BPer (Figure 3(a) and Figure 3(b)) having all samples clustering around the pyrogenic section also support this PAHs source identification status for the two cores.

\subsection{Potential Toxicological Significance}

\subsubsection{Assessment of Toxicity Potential by Toxicity Unit Indices}

In the study, potential risk was assessed by comparing the present data with sediment quality guidelines (SQGs) of the Canadian Council of Environment (CCME, 2002). Two toxicity unit indices (TU1 and TU2) for the most recent top layer and sub-layers of both RS and RC were generated from the Interim SQG

Table 2. Characteristic PAH molecular diagnostic ratios.

\begin{tabular}{|c|c|c|c|c|}
\hline PAHs & Petrogenic & Pyrogenic & Results from RC core & Results from RS core \\
\hline Ant/Ant + Phe & $<0.1$ & $>0.1$ & $0.67 \pm 0.03(0.62-0.70)$ & $0.35 \pm 0.05(0.04-0.28)$ \\
\hline $\mathrm{BaA} / \mathrm{BaA}+\mathrm{Chry}$ & $<0.2$ & $>0.35$ & $0.47 \pm 0.00(0.48-0.49)$ & $0.47 \pm 0.01(0.48-0.50)$ \\
\hline $\mathrm{Fl} / \mathrm{Fl}+\mathrm{Pyr}$ & $<0.4$ & $>0.4$ & $0.54 \pm 0.09(0.48-0.71)$ & $0.52 \pm 0.02(0.48-0.54)$ \\
\hline \multirow[t]{2}{*}{$\mathrm{Icdp} / \mathrm{Icdp}+\mathrm{BPer}$} & $<0.2$ & $>0.2$ & $0.65 \pm 0.02(0.63-0.68)$ & $0.61 \pm 0.04(0.56-0.65)$ \\
\hline & Fuel combustion & Grass/Coal/Wood combustion & & \\
\hline $\mathrm{Fl} / \mathrm{Fl}+\mathrm{Pyr}$ & $0.4-0.5$ & $>0.5$ & $0.54 \pm 0.09(0.48-0.71)$ & $0.52 \pm 0.02(0.48-0.54)$ \\
\hline $\mathrm{Icdp} / \mathrm{Icdp}+\mathrm{BPer}$ & $0.2-0.5$ & $>0.5$ & $0.65 \pm 0.02(0.63-0.68)$ & $0.61 \pm 0.04(0.56-0.65)$ \\
\hline
\end{tabular}




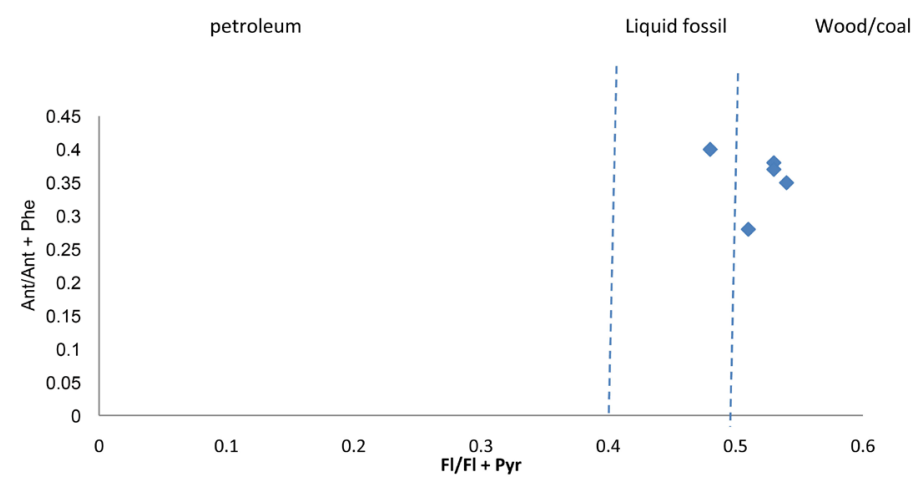

(a)

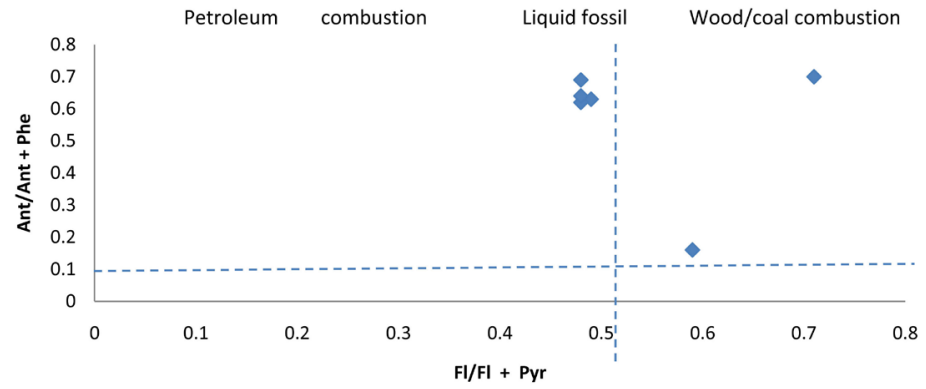

(b)

Figure 2. (a), (b): Boundary crossplot of Ant/Ant + Phe versus Fl/Fl + Pyr for (a) RS and (b) RC cores.

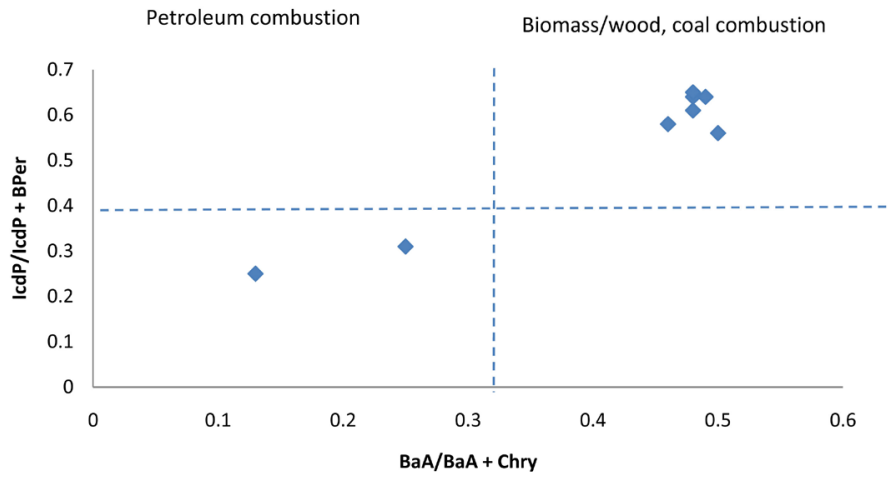

(a)

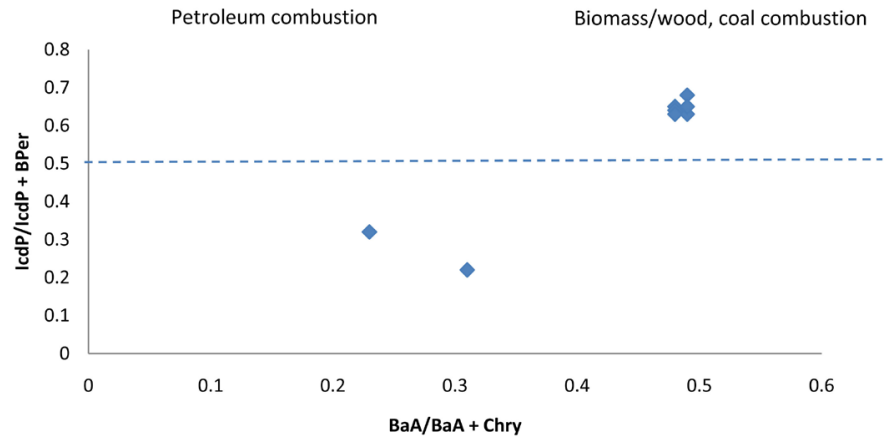

(b)

Figure 3. (a), (b): Boundary crosss plot of IcdP/IcdP + BPer versus BaA/BaA + Chry for (a) RS and (b) RC cores. 
and probable effects level (PEL) of CCME (2002). Calculation of TU1 was based on the summed ratios between the concentrations of each individual PAH and their corresponding ISQGs, whereas calculation of TU2 was achieved from the summed ratios between the concentrations of individual PAHs and PEL values. Summation of TU1 and TU2 produced a rough estimate of the toxicity of the whole PAH distribution. While TU1 is measuring the deviation of the distribution from a reference of no effect, TU2 assesses the extent to which toxic effect is observed according to the sedimentary PAH content.

TU1 and TU2 values for the study are presented in Figure 4(a) and Figure 4(b). These indices indicated the deviation of sedimentary PAHs content from level of no effect. The RS exhibited TU1 values ranging from 1.27 (RS1; $0-5 \mathrm{~cm}$; $\sim 1997-2014$ ) to 1.51 (RS5; $20-25 \mathrm{~cm} ; 1930-1947)$ with a mean $1.37 \pm 0.09$, while the TU1 values ranging from 1.22 (RC3 and RC4; $10-20 \mathrm{~cm}$; 1948-1981) to 1.48 (RC2; $5-10 \mathrm{~cm}$; 1981-1998) was calculated for the RC (mean $1.31 \pm$ 0.10). Both cores had total TU1 values higher than 1 at all depth intervals indicating that PAH levels in these sediment layers exceeded the levels of no effect. The highest TU1 value found in the near-bottom layer (RS5, $20-25 \mathrm{~cm}$ ) of the RS corresponding to geological time-frame $\sim 1930-1947$ coincided with the period of European occupation of the lake's catchments when domestic coal or coal products utilization and wood/grass burning for recreational purposes, respectively were at their peak. The implication here is that the resident fauna and flora must have experienced higher PAHs toxicity effects at $\sim 70 \mathrm{yr}$. ago than in the recent time. Both cores had total TU1 values higher than 1 at all depth interval indicating that PAH levels in these sediment layers exceeded the levels of no effect.

TU2 index revealed PAH contents for which effects on organisms and plants are likely. Interestingly, total TU2 values for both RS and RC were lower than 1 at all depth intervals, revealing unlikely PAH effects to benthic fauna and flora within the ecosystem.

\subsubsection{Assessment of Sediment Quality Using Biological Thresholds}

Another approach for the assessment of potential toxicological impacts is the application of biological thresholds. The effects-range low (ERL) and effects-range median (ERM) values calculated by (Oyo-ita et al., 2017) were adopted for the assessment of Refome lake sediment quality. ERL and ERM

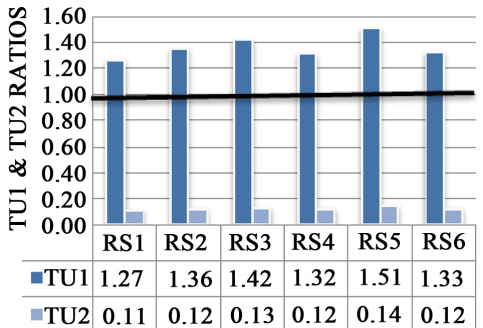

(a)

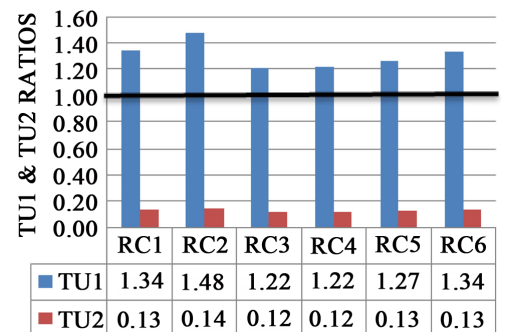

(b)

Figure 4. (a), (b): Total TU1 and TU2 index values for (a) RS and (b) RC cores. 
values are expected to define PAHs concentration ranges that are not often or frequently attributable to adverse biologic effects. In this study, the measured PAHs concentrations were compared with ERL and ERM values to obtain hazard ratios (MSC/ERL and MSC/ERM) representing the ratios of measured sedimentary concentrations of individual PAH compounds to the respective ERL and ERM values. In principle, MSC/ERL or MSC/ERM $<1$, would indicate that adverse biological effects are rarely attributable to the PAHs levels. On the contrary, MSC/ERL or MSC/ERM > 1, would portray that adverse biologic effects are occasionally or frequently attributable to PAHs levels. Interestingly, MSC/ERL and MSC/ERM hazard ratios were all $<1$ for measured individual PAHs for the most recent top layers of both cores (Figure 5(a) and Figure 5(b)). The result indicated that concentrations of these PAHs in surface sediment would not pose any adverse biological effects on resident fauna and flora.

\subsubsection{Assessment of Sediment Quality Based on Risk Quotient}

The assessment of the potential environmental risk attributable to PAHs deposition in surface sediment of the lake was performed and the results are presented in Table 3. Sediment quality assessment methods rely on chemical approach where total environmental concentrations are measured or predicted and then compared to available reference, target or recommended values.

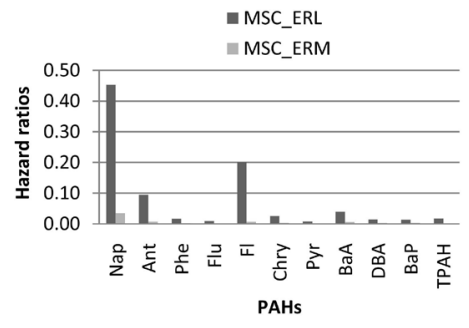

(a)

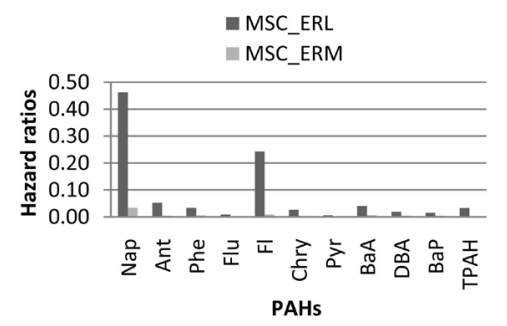

(b)

Figure 5. (a), (b): Risk assessment of PAHs hazard ratios in (a) RC and (b) RS cores.

Table 3. Risk quotient and toxic benzo (a) pyrene equivalency factors (ng/g TEqF) assessment values for the most recent top layers of RS and RC cores.

\begin{tabular}{ccccccccccccc}
\hline PAH & HDC & LDC & TEL & PEL & SQG & MSC $_{H}$ & MSC $_{\mathrm{L}}$ & Qs $_{H}$ & Qs $_{\mathrm{L}}$ & TEqFR & TEqF $_{\text {Rc1 }}$ \\
\hline B(a)P & 5.51 & 8.62 & 32.1 & 782 & 0.04 & 0.08 & 0.08 & 2.00 & 2.00 & $5.91(63.62 \%)$ & $6.23(68.10 \%)$ \\
DBA & 1.12 & 0.89 & 6.22 & 135 & 0.05 & 0.01 & 0.012 & 0.20 & 0.24 & $1.32(14.17 \%)$ & $0.85(9.27 \%)$ \\
Chry & 10.24 & 9.64 & 57.1 & 86.2 & 0.66 & 0.095 & 0.13 & 0.14 & 0.20 & $0.01(0.11 \%)$ & $0.01(0.11 \%)$ \\
Ant & 7.95 & 4.47 & 46.9 & 245 & 0.19 & 0.11 & 0.04 & 0.58 & 0.21 & NA & NA \\
B(a)A & 10.24 & 10.04 & 31.7 & 38.5 & 0.08 & 0.14 & 0.09 & 1.75 & 1.13 & $1.01(10.83 \%)$ & $1.02(11.14 \%)$ \\
Flu & 5.88 & 4.74 & 111 & 2355 & 0.05 & 0.081 & 0.041 & 1.60 & 0.82 & NA & NA \\
Fl & 3.79 & 3.67 & 21.2 & 144 & 0.14 & 0.052 & 0.03 & 0.37 & 0.37 & NA & NA \\
Phen & 6.49 & 4.14 & 41.9 & 51.5 & 0.08 & 0.06 & 0.06 & 0.75 & 0.75 & NA & NA \\
Pyr & 5.41 & 3.44 & 53 & 875 & 0.06 & 0.05 & 0.05 & 0.83 & 0.82 & NA & NA \\
IcdP & 10.66 & 10.39 & 200 & 3200 & 0.06 & 0.14 & 0.09 & 2.31 & 1.61 & $1.05(11.33 \%)$ & $1.05(11.46 \%)$ \\
Total TEqF & NA & NA & NA & NA & NA & NA & NA & NA & NA & 9.29 & 9.16 \\
\hline
\end{tabular}

NB: NA = Not applicable; values in parenthesis = percentage contribution of individual TEqFs to total TeqFs. 
Sediment quality values (TEL-Threshold Effect Level and PEL-Probable Effect Level) used to calculate sediment quality guidelines (SQG-TEL/PEL; CCME, 2002) and by extension risk quotients (Qs) was obtained from the US NOAA, 1998. Qs for chemicals in the sediment were calculated according to the expression as follows:

$$
\text { Qs }=\text { MSC/SQC }
$$

where MSC is measured sedimentary concentration (in total sediment) for a substance and SQC is sediment quality criteria for the substance (sediment quality concentration $=$ SQG). TEL and PEL values are meant to define concentration ranges of chemical that are frequently or rarely attributable to adverse biologic effects NOAA, 1998). Only contaminants for which sediment quality data are available were assessed in the study.

The sediment quality assessment was performed only for the top layers (0 - 5 $\mathrm{cm}$ ) of the two cores where resident fauna and flora mainly thrive, related to contaminants lowest determined concentration (LDC) and highest determined concentration (HDC). The values were used in determining the measured sedimentary concentrations for low and high case scenarios accordingly (MSCL and $\mathrm{MSCH})$ ). In the study, the measured PAHs concentrations were compared with TEL and PEL values to obtain Qs. If Qs are $<1$, adverse biologic effects are rarely attributable to $\mathrm{PAHs}$ contaminations. If $\mathrm{Q} s$ are $>1$, adverse biologic effects are frequently attributable to PAHs contaminations.

The results indicated that most contaminants in the two sites (RS and RC) posed no severe biologic effects because the estimated values of Qs for these chemicals were less than 1, except for $\mathrm{Fl}, \mathrm{BaA}, \mathrm{BaPyr}$ and IcdP with Qs greater than 1 (Table 3 ). These chemicals therefore would probably pose some degree of risk to the resident organisms. Hence, a more robust risk assessment should be undertaken in order to ascertain the risk associated with these chemicals.

\subsubsection{Assessment of Sediment Quality Based on Toxicity Equivalent Factor}

Another method used for the assessment of quality of sediment is based on toxic equivalent factors (TEFs) determination. This approach dwells specifically on seven carcinogenic PAHs (c-PAHs) such as Chry, BaA, BkF, BbF, BaP, IcdP and DBA. BaPyr is the only PAH with very high toxicity and desirable carcinogenic potency factor (Peters et al., 2011). The toxicity equivalency factors (TEqFs) were used to identify other c-PAHs in relation to BaPyr and equally ascertain the BaPyr equivalent doses -BaPyr-Eqdose (Nadal et al., 2004). Estimated toxic equivalent factors (TEFs) courtesy of some PAHs are viz; $\mathrm{BaA}(1), \mathrm{BaPyr}(0.1)$, $\mathrm{BbF}$ (0.1), BkF (0.1), IcdP (0.1), DBA (1) and Chry (0.001).

In the study, converting the above six (6) PAHs concentrations into the corresponding toxic BaPyr equivalency factors (TEqFs) was achieved as follows:

$$
\text { TEqFs }=\sum(\mathrm{M} \times \mathrm{TEFs})
$$

where $\mathrm{M}=$ concentration of $\mathrm{PAH}$ in $\mathrm{ng} / \mathrm{g}$. Total TEqFs calculated for RS and RC 
sites were $9.29 \mathrm{ng} / \mathrm{g}$ TEqFs and $9.16 \mathrm{ng} / \mathrm{g} \mathrm{TEqFs}$, respectively (Table 3). The United State Department of Ecology uses the total toxic equivalency factor (TEqF) approach to estimate the toxicity and asses the risks associated with mixtures of c-PAHs. Based on the United State Environmental Protection Agency (US EPA), estimated value for the clean-up level of a mixture of c-PAHs in relation to BaPyr is $137 \mathrm{ng} / \mathrm{gTEqF}$. The values for the surface sediment of the present study were less than the recommended toxic level. Hence, the c-PAHs in the study area may not pose severe environmental threat to the residents.

The contribution to the total $\mathrm{TE}_{\mathrm{Q}} \mathrm{Fs}$ for the 6 individual c-PAHs decreasedin the following order for RS site: BaPyr $(63.62 \%)>\mathrm{DBA}(14.17 \%)>\operatorname{IcdP}$ $(11.33 \%)>\mathrm{BaA}(10.83 \%)>\mathrm{Chry}(0.11 \%)$. Those for the RC site were in the decreasing order as follows: $\operatorname{BaPyr}(68.10 \%)>\operatorname{IcdP}(11.46 \%)>\mathrm{BaA}(11.14 \%)>$ DBA $(9.27 \%)>$ Chry $(0.11 \%)$. The result indicated that more public attention should be paid to BaPyr accumulation in the lake's sediment.

Comparing data with other regions of the world, considerably higher TEqFs were reported for surface sediment from lake Hongfeng (China; e.g. $334.3 \mathrm{ng} / \mathrm{g}$ TEQF; Guo et al., 2011); oil-polluted intertidal sediments from Yeosu Bay, South Korea Lee et al., 1997; surface sediments from Taihu Lake (China; e.g. 94 - 856 ng/g TEQF; Qiao et al., 2005); thus, highlighting the relatively lower toxicity potential of c-PAHs in the study area.

\section{Conclusion}

Several assessment methods have been used to assess the toxicity potential of sedimentary PAHs in two cores from Refome lake, SE Nigeria. Results of TU1 revealed values higher than the threshold of no effect with the highest value recorded at $\sim 70 \mathrm{yr}$, ago that coincided with the period of inhabitation by the European settlers when coal utilization and biomass burning were at their peak. TU2 exhibited values that were below the index of probable effect which implied unlikely PAH effects to benthic organisms within the ecosystem. Similar trend was found for other indices such as hazard ratios (MSC/ERL and MSC/ERM), risk quotients (Qs) and toxicity equivalency factors (TEqFs) in surface sediment of the two cores except that more public attention is required for BaPyr accumulation in the case of TEqFs for the lake's sediment.

PAHs source characterization by molecular ratios with the corresponding boundary cross plots indicated that PAHs inputs originated mainly from domestic coal utilization and biomass burning.

\section{Acknowledgements}

We are thankful to European Association of Organic Geochemist (EAOG-Travel Scholarship Award, 2012) for the financial support. Institute of Environmental Assessment and Water Research, Spanish Council of Scientific Research (CSIC) Barcelona, Spain and ADECYTE are also acknowledged for additional financial support and provision of excellent research facilities. We also appreciate the as- 
sistance of Dr. Pere Masque of the Department de Fisica-Institut Cienciai Technologia Ambientals, Universiat Bellaterra, Spain in carrying out radiometric dates of our samples at little or no cost, facilitated by J. Bayona and J. Albeiges.

\section{Conflicts of Interest}

The authors declare no conflict of interest.

\section{References}

Appleby, P. G. (1998). Dating Recent Sediments by ${ }^{210} \mathrm{~Pb}$ : Problems and Solutions. In 2 nd NKS/EKO-1 Seminar (pp. 7-24). Helsinki: STUK.

Canadian Council of Ministers of the Environment (CCME) (2002). Canadian Sediment Quality Guidelines for the Protection of Aquatic Life: Summary Tables, Updated.

Christensen, E. R., \& Arora, S. (2007). Source Apportionment of PAHs in Sediments Using Factor Analysis by Time Records: Application to Lake Michigan, USA. Water Research, 23, 1-8. https://doi.org/10.1016/j.watres.2006.09.009

Cross River Basin Development Authority (CRBDA) (1982). Inventory of Natural Site Conditions: Slopes, Hydrology, Land Use and Vegetation Progress Report 4 (pp. 1-146).

Ekwueme, B. N., Nyong, E. E., \& Petters, S. W. (1995). Geological Excursion Guidebook to Oban Massif, Calabar Flank, Ikom-Mamfe Embayment and Southeastern Nigeria. Calabar: Dec-Ford Publishers.

Guo, J.-Y., Wu, F.-C., Zhang, L., Liao, H.-Q., Zhang, R.-Y., Li, W., Zhao, X.-L., Chen, S.-J., \& Mai, B. X. (2011). Screening Level of PAHs in Sediment Core from Lake Hongfeng. Archives of Environmental Contamination and Toxicology, 60, 590-596. https://doi.org/10.1007/s00244-010-9568-4

Lee, M. L., Prado, G. P., Howard, J. B., \& Hites, R. A. (1997). Source Identification of Urban Airborne Polycyclic Aromatic Hydrocarbons by Gas Chromatography-Mass Spectrometry and High Resolution Mass Spectrometry. Biomedical Mass Spectrometry, 4, 182-186. https://doi.org/10.1002/bms.1200040311

Liu, Z., Zhang, H., Tao, M., Yang, S., Wang, L., Liu, Y., Ma, D., \& He, Z. (2007). Organochlorine Pesticides in Consumer Fish and Mollusk of Liaoning Province, China: Distribution and Human Exposure Implication. Archives of Environmental Contamination and Toxicology, 59, 444-453. https://doi.org/10.1007/s00244-010-9504-7

Nadal, M., Schuhmancher, M., \& Dominguez, J. L. (2004). Levels of PAHs in Soils and Vegetation Samples from Tarragona County, Spain. Environmental Pollution, 132, 1-11. https://doi.org/10.1016/j.envpol.2004.04.003

National Oceanic and Atmospheric Administration (NOAA) (1998). The National Status and Trends Programs for Marine Environmental Quality (32 p.). Silver Spring, MD: NOAA National Ocean Service, National Centres for Coastal Ocean Science.

Office Federal de la protection de l'Environment (OEaux) (1998). Ordinance $d u 28$ October 1998 sur la protection des eaux. No. RS814.201, Berne.

Oyo-ita, I. O., Oyo-ita, O. E., Ekpo, O. I., Sam, E. S., \& Ugim, S. U. (2017). Source Characterization and Historical Trend of Sedimentary PAHs from Refome Lake, South-South Nigeria. Aquatic Geochemistry, 23, 377-398.

https://doi.org/10.1007/s10498-017-9327-5

Oyo-Ita, O. E., \& Oyo-Ita, I. O. (2012). PAHs Depositional History in Recent Core Sedi- 
ments from Ukwa Ibom Lake, SE Nigeria. Environmental Geochemistry \& Health, 35, 189-199. https://doi.org/10.1007/s10653-012-9475-X

Oyo-Ita, O. E., Offem, J. O., Ekpo, B. O., \& Adie, P. A. (2013). Anthropogenic PAHs in Mangrove Sediments of the Calabar River, S.E. Niger Delta, Nigeria. Applied Geochemistry, 28, 212-219. https://doi.org/10.1016/j.apgeochem.2012.09.011

Oyo-ita, O. E., Oyo-ita, I. O., Sam, E. S., Ekpo, O. I., \& Ugim, S. U. (2016). Natural and Anthropogenic Biomarkers in Recent Dated Sediment Cores from Reforme Lake, SE Nigeria: Environmental Implications. Environmental Earth Science, 75, 1-14. https://doi.org/10.1007/s12665-016-6257-2

Qiao, I., Wang, C., Huang, S., Wang, D., \& Wang, Z. (2005). Composition, Sources and Toxicological Significance of PAHs in the Surface Sediments of the Meiliang Bay, Taihu Lake, China. Environment International, 32, 28-33.

https://doi.org/10.1016/j.envint.2005.04.005

Romano, S., Fro, M. L., Marsella, E., \& Nhon, D. H. (2008). Presence and Origin of Polycyclic Aromatic Hydrocarbons in Sediments of Nine Coastal Lagoons in Central Vietnam. Marine Pollution Bulletin, 56, 1504-1512.

https://doi.org/10.1016/j.marpolbul.2008.04.013

Shi, W., Sun, M. Y., Molina, M., \& Hodson, R. E. (2006). Variability in the Distribution of Lipid Biomarkers and Their Molecular Isotopic Composition in Altamaha Estuarine Sediments: Implications for the Relative Contribution of Organic Matter from Various Sources. Organic Geochemistry, 32, 453-467.

https://doi.org/10.1016/S0146-6380(00)00189-3

Silliman, J. E., \& Shelske, C. L. (2003). Saturated Hydrocarbons in the Sediments of Lake Apopka, Florida. Organic Geochemistry, 34, 253-260.

https://doi.org/10.1016/S0146-6380(02)00169-9 